\title{
BMJ Open Changes in prevalence of workplace violence against doctors in all medical specialties in Norway between 1993 and 2014: a repeated cross-sectional survey
}

\author{
Ingrid Hjulstad Johansen, ${ }^{1}$ Valborg Baste, ${ }^{1}$ Judith Rosta, ${ }^{2}$ Olaf G Aasland, ${ }^{2}$ \\ Tone Morken ${ }^{1}$
}

To cite: Johansen IH, Baste V, Rosta J, et al. Changes in prevalence of workplace violence against doctors in all medical specialties in Norway between 1993 and 2014: a repeated crosssectional survey. BMJ Open 2017;7:e017757. doi:10.1136/ bmjopen-2017-017757

- Prepublication history for this paper is available online To view these files please visit the journal online (http://dx.doi org/10.1136/bmjopen-2017017757).

Received 15 May 2017 Revised 22 June 2017 Accepted 7 July 2017

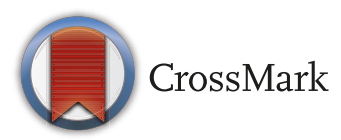

${ }^{1}$ National Centre for Emergency Primary Health Care, Uni Research Health, Bergen, Norway

${ }^{2}$ Institute for Studies of the Medical Profession, 0slo, Norway

Correspondence to Dr. Ingrid Hjulstad Johansen; ingrid.johansen@uni.no

\section{ABSTRACT}

Objectives The aim of this study was to investigate whether reported prevalence of experienced threats, real acts of violence and debilitating fear of violence among Norwegian doctors have increased over the last two decades.

Design Repeated cross-sectional survey.

Setting All healthcare levels and medical specialties in Norway.

Participants Representative samples of Norwegian doctors in $1993(n=2628)$ and $2014(n=1158)$.

Main outcome measures Relative risk (RR) of selfreported prevalence of work-time experiences of threats and real acts of violence, and of being physically or psychologically unfit during the last 12 months due to fear of violence, in 2014 compared with 1993, adjusted by age, gender and medical specialty.

Results There were no differences in self-reported threats (adjusted RR $=1.01,95 \% \mathrm{Cl} 0.95$ to 1.08) or real acts (adjusted RR $=0.90,95 \% \mathrm{Cl} 0.80$ to 1.03) of violence when comparing 2014 with 1993. The proportion of doctors who had felt unfit due to fear of violence decreased from 1993 to 2014 (adjusted RR=0.53, 95\% $\mathrm{Cl} 0.39$ to 0.73 ). Although still above average, the proportion of doctors in psychiatry who reported real acts of violence decreased substantially from 1993 to 2014 (adjusted RR=0.75, 95\% $\mathrm{Cl} 0.60$ to 0.95).

Conclusions A substantial proportion of doctors experience threats and real acts of violence during their work-time career, but there was no evidence that workplace violence has increased over the last two decades. Still, the issue needs to be addressed as part of the doctors' education and within work settings.

\section{INTRODUCTION}

Workplace violence is unavoidable in healthcare settings, and there is a general belief that it is increasing. ${ }^{1-3}$ In the period of 2011 till 2014, the Norwegian Labour Inspection Authority reported a doubled incidence of registered injuries on employees due to violence at work. ${ }^{4}$ Similar trends have been reported from the USA, ${ }^{5}$ Asia, ${ }^{6}$ England $^{7}$ and generally across Europe. ${ }^{1}$

\section{Strengths and limitations of this study}

- The study investigates long-term changes in selfreported prevalence of workplace violence and has an observation time of two decades.

- The study has large representative samples and high response rates.

- The two surveys had comparable items on violence against doctors.

- The validity of the surveys was limited by recall bias due to having asked about work career prevalence instead of prevalence over a shorter, defined and recent time period.

- The surveys included no definition of threats and violence, and the answers therefore depended on the doctors' subjective definition.

Although less exposed than nurses and other auxiliary personnel, numerous studies from across the world have found that doctors are at risk of being victims of workplace violence, for example refs 8-19. Experiences of violence seem to lower work performance, ${ }^{20-22}$ lower job satisfaction, ${ }^{23-25}$ increase apprehensiveness ${ }^{10} 1520$ and affect physical and mental health negatively, ${ }^{23} 25-28$ especially during the first couple of years after the violent incident. ${ }^{26}$ Further, experiences of violence seem to increase job turnover intention $^{152324}$ and affect doctors' willingness to participate in out-of-hours care. ${ }^{29-33}$ It seems that younger or less experienced doctors are more exposed to violence than older or more experienced doctors. ${ }^{1115172634-36}$ Male doctors are more exposed than females. ${ }^{9} 11173435$ Doctors working in psychiatry, ${ }^{9} 232634$ accident and emergency medicine ${ }^{9} 232634$ and general practice ${ }^{34}$ seem to be more exposed than doctors working in other settings.

In Norway, the medical healthcare system is two tiered, and general practitioners are gatekeepers to all secondary care, including 
emergency psychiatric care. This implies that general practitioners provide initial care to an unselected group of patients and that there are no walk-in emergency rooms at psychiatric or somatic hospitals. In hospitals, all clinical doctors take turns in attending to the emergency patients referred to their specialty, as part of their duty. Accident and emergency medicine has not been a medical specialty. Furthermore, to obtain their licence for independent clinical work, all medical students have to do internships in internal medicine, surgery and general practice. Thus, all doctors, independent of medical specialty, have altogether 1.5 years experience of clinical work within these disciplines before chosen medical specialisation. Much of the time during the internship is allocated to supervised examination and treatment of newly arrived medical and surgical patients at the hospital, and provision of emergency and urgent care while in general practice.

With few exceptions, most studies on workplace violence have been limited to one level of the healthcare system, one medical specialty or one measurement at a single point in time. We therefore wanted to investigate how the prevalence of violence against doctors has changed over time, and whether there are differences between subgroups of doctors. The aims of this study were therefore to describe changes over a period of 20 years in self-reported prevalence of experienced threats of violence, real acts of violence and debilitating fear of violence among Norwegian doctors in all medical specialties.

\section{METHODS}

This study is a repeated cross-sectional survey based on data from the Institute for Studies of the Medical Profession (LEFO), Oslo, Norway (www.legeforsk.org). In 1993, 9266 doctors were invited to participate in an extensive cross-sectional survey, and 6652 doctors responded, giving an overall response rate of $71.8 \%$. This survey used an overlapping questionnaire design, in which 4 out of 16 different questionnaires were completed by randomly selected subsets of doctors. ${ }^{37}$ Questions on experienced violence were included in one of the cross-sectional questionnaires. This particular questionnaire was sent to 3608 doctors, and 2628 doctors responded (72.8\%). The respondents were representative for Norwegian doctors in $1993 .^{37}$

In addition, LEFO established a representative cohort of approximately 2000 doctors in 1994 (the reference panel of doctors).$^{38}$ The panel did not include any individuals from the cross-sectional sample from 1993. Over time, retired doctors have been removed from the panel, and new young doctors were added. The reference panel has been surveyed biannually since 1994. The themes of these repeated surveys vary, although some core questions on specialty, workload and work situation are always included. Questions on experienced violence were included in 2014. In 2014, 1545 doctors were invited to answer the survey, and 1158 responded $(75.0 \%)$. The respondents were representative for Norwegian doctors in $2014 . .^{39} 40$

The following questions were asked about workplace violence:

- Have you experienced threats of violence from patients or other 'visitors'?

- Have you experienced real acts of violence from patients or other 'visitors'?

- During the last year, have you felt physically or psychologically unfit due to fear of experiencing violence at work?

In Norwegian, 'real acts of violence' signifies physical violence, and we have chosen to use the Norwegian term when describing the results.

The questions about experienced threats and about real acts of violence had the response categories 'never', 'once', 'two or three times' and 'more than three times'. The variables were analysed both with four categories and dichotomised into 'no' (never) and 'yes' (all other alternatives). The question about 'physical or psychological unfitness due to fear of experiencing violence' had different response alternatives in 1993 (never, rarely, sometimes, rather often) and in 2014 (never, once, two or three times, more than three times). Before analysis, the answers were therefore recoded into 'no' (never) and 'yes' (all other alternatives).

Information about the doctors' age, gender and medical specialty was collected. The question on specialties was posed differently in 1993, compared with 2014. Both years, the doctors were asked to name their main present work position. In 1993, the doctors were additionally asked about which medical specialty they had qualified in; while in 2014, the doctors were asked about with which specialty their main position was affiliated. In the 1993 sample, 1060 doctors had not yet qualified for a medical specialty. When possible, these were recoded into specialties using the information they had given about their main work position. However, after recoding, there were still 408 junior doctors who had unknown affiliation to a specialty.

In 2014, there were 44 different medical specialties in Norway. Before the statistical analysis, the specialties were pooled into the following groups:

- General practice

- Laboratory medicine, including immunology, clinical physiology, clinical biochemistry, clinical neurophysiology, medical genetics, medical microbiology, radiology, pathology, clinical pharmacology, anatomy, biochemistry and physiology

- Internal medicine, including paediatrics, physical medicine and rehabilitation, dermatology and venereology, internal medicine, haematology, endocrinology, gastroenterology, geriatrics, neurology, nephrology, rheumatology, oncology, ophthalmology and tropical medicine

- Surgery, including anaesthesiology, obstetrics and gynaecology, general surgery, vascular surgery, ortho- 
Table 1 Characteristics of the doctors by gender and medical specialty in $1993(n=2628)$ and $2014(n=1158)$

\begin{tabular}{|c|c|c|c|c|c|}
\hline \multirow[b]{2}{*}{ Characteristics } & \multicolumn{2}{|c|}{1993} & \multicolumn{2}{|c|}{2014} & \multirow[b]{2}{*}{ p Value } \\
\hline & $\mathbf{n}$ & $\%$ & $\mathbf{n}$ & $\%$ & \\
\hline Gender & & & & & $<0.001$ \\
\hline Male & 1857 & 70.9 & 664 & 57.8 & \\
\hline Female & 763 & 29.1 & 484 & 42.2 & \\
\hline (Missing) & (8) & & (10) & & \\
\hline Specialty & & & & & $<0.001$ \\
\hline General practice & 869 & 34.8 & 272 & 24.5 & \\
\hline Laboratory medicine & 132 & 5.3 & 80 & 7.2 & \\
\hline Internal medicine & 402 & 16.1 & 321 & 28.9 & \\
\hline Surgery & 385 & 15.4 & 207 & 18.6 & \\
\hline Psychiatry & 150 & 6.0 & 145 & 13.1 & \\
\hline Public health & 153 & 6.1 & 54 & 4.9 & \\
\hline Others & 408 & 16.3 & 31 & 2.8 & \\
\hline (Missing) & (129) & & $(48)$ & & \\
\hline
\end{tabular}

paedic surgery, urology, maxillofacial surgery, neurosurgery, plastic surgery and otorhinolaryngology

- Psychiatry, including specialists in child, adolescence and adult psychiatry

- Public health, including occupational medicine

- Others, including administrative, academic and junior doctors with unknown affiliation to specialty

During the two decades, there has been changes within medical specialties as to how much patient contact the doctors have. We chose to retain the originally used categorisation from 1993, where, for example, radiology was a specialty without direct contact with patients and therefore classified under laboratory medicine. ${ }^{37}$

Descriptive statistics were given as mean, SD and percentages (\%). Differences between 1993 and 2014 and associations between year and workplace were tested with $\chi^{2}$ tests, and differences in continuous variables with independent t-tests. For the dichotomised outcome variables, log-binomial regressions were performed to estimate relative risk (RR) with $95 \%$ CI for the self-reported experience in 2014 relative to 1993, controlled for gender, age and specialty. The analyses were performed using IBM SPSS Statistics V.24.

\section{RESULTS}

As shown in table 1, the proportion of female doctors increased from 1993 to 2014. The distribution between specialties also changed, partly due to more doctors in the others category in 1993. Fewer doctors worked in general practice in 2014 compared with 1993. Mean age was lower in 1993 (42.8 years, $\mathrm{SD}=9.6$ ) compared with 2014 (49.6 years, $\mathrm{SD}=11.5)(\mathrm{p}<0.001)$. In 1993, age ranged between 25.0 and 69.0 years; whereas, in 2014, age ranged between 25.0 and 76.0 years.
Changes in self-reported experiences of threats and real acts of violence between 1993 and 2014

In 1993, 2551 out of 2628 doctors answered the question on experiences of threats of violence $(2.9 \%$ missing), and 1341 doctors $(52.6 \%)$ had experienced threats at least once. The corresponding numbers for 2014 were 1143 out of 1158 doctors (1.3\% missing), and 578 doctors (50.6\%) had experienced threats at least once. In 1993, 2491 out of 2628 doctors answered the question on experiences of real acts of violence (5.2\% missing), and 629 doctors (25.3\%) had experienced real acts of violence at least once. In 2014, the corresponding numbers were 1132 out of 1158 doctors (2.2\% missing), and 270 doctors (23.9\%) had experienced real acts of violence at least once. When comparing 2014 with 1993, there were no differences in experienced threats (adjusted RR $=1.01,95 \%$ CI 0.95 to 1.08 ) or real acts of violence (adjusted $\mathrm{RR}=0.90,95 \%$ CI 0.80 to 1.03 ). However, taking into account number of episodes, there was a slight, but significant, difference between 1993 and 2014 (table 2). Fewer doctors reported more than three threats of violence in 2014 compared with 1993. The same pattern was found for real acts of violence. These findings were unchanged when adjusted for gender, age and specialty.

In 1993, 2601 out of 2628 doctors had answered the question on feeling unfit due to fear of violence $(1.0 \%$ missing), whereas in 2014, 1109 out of 1158 had answered this question (4.2\% missing). The proportion of doctors who had felt unfit due to fear of violence decreased from $10.4 \%$ in 1993 to $4.6 \%$ in 2014 (table 2). The RR was 0.53 (95\% CI 0.39 to 0.73 ) in 2014 compared with 1993, adjusted for gender, age and specialty.

\section{Changes in self-reported experiences of threats or real acts of violence between 1993 and 2014 in relation to age, gender} and medical specialty of the doctors

Table 3 shows the proportion of doctors who had experienced threats or violence in 1993 and 2014 by gender, age group and specialty. Within each gender, the proportion of doctors having experienced threats or violence did not change between 1993 and 2014. Further, there was no significant difference between male and female doctors regarding change in threats or real acts of violence reported between the two decades (analyses not shown).

In general, there were more exposure to threats and real acts violence with increasing age. The exception to this general trend was in 1993, where the oldest group of doctors reported less threats and violence than the two younger groups of doctors. In the oldest age group ( 55 years and older), there was an increase in RR of experiences of threats, whereas in the youngest group the risk for acts of violence was decreased in 2014 compared with 1993.

Psychiatry was the specialty with highest occurrence of reported violence and threats independent of year. The proportion of psychiatrists who had experienced violence was significantly lower in 2014 compared with 1993. Although low overall occurrence, there was an opposite 
Table 2 Reported experiences of threats or real acts of violence, and feeling unfit due to fear of violence, in $1993(n=2628)$ and $2014(n=1158)$

\begin{tabular}{|c|c|c|c|c|c|}
\hline & \multicolumn{2}{|c|}{1993} & \multicolumn{2}{|c|}{2014} & \multirow[b]{2}{*}{ p Value } \\
\hline & $\mathbf{n}$ & $\%$ & $\mathbf{n}$ & $\%$ & \\
\hline Experienced threats of violence & & & & & 0.007 \\
\hline Never & 1210 & 47.4 & 565 & 49.4 & \\
\hline Once & 382 & 15.0 & 193 & 16.9 & \\
\hline $2-3$ times & 586 & 23.0 & 264 & 23.1 & \\
\hline$>3$ times & 373 & 14.6 & 121 & 10.6 & \\
\hline (Missing) & (77) & & (15) & & \\
\hline Experienced real acts of violence & & & & & $<0.001$ \\
\hline Never & 1862 & 74.7 & 862 & 76.1 & \\
\hline Once & 328 & 13.2 & 186 & 16.4 & \\
\hline $2-3$ times & 223 & 9.0 & 64 & 5.7 & \\
\hline$>3$ times & 78 & 3.1 & 20 & 1.8 & \\
\hline (Missing) & (137) & & (26) & & \\
\hline Unfit due to fear of violence at least once during the last year & & & & & $<0.001$ \\
\hline No & 2331 & 89.6 & 1058 & 95.4 & \\
\hline Once or more & 270 & 10.4 & 51 & 4.6 & \\
\hline (Missing) & (27) & & (49) & & \\
\hline
\end{tabular}

finding regarding threats of violence among doctors working in laboratory medicine.

\section{DISCUSSION}

Our study found no change between 1993 and 2014 in the proportion of doctors who reported being exposed to threats or real acts of violence during their work career. Fewer doctors reported being physically or psychologically unfit during the last 12 months due to fear of violence in 2014 compared with 1993. The proportion of psychiatrists who reported real acts of violence decreased substantially from 1993 to 2014, although they reported the highest prevalence of violence in both samples. There was an opposite effect for threats of violence within laboratory medicine.

\section{Strengths and limitations of the study}

The main strength of our study is the large, representative samples with high response rates, making the results generalisable to the entire population of doctors in Norway. ${ }^{3738}$ The advantage of similarities in the two surveys and comparable items on violence against doctors over a time span of 20 years should also be pointed out. The validity of the study was limited by having asked about work career prevalence instead of prevalence over a shorter and defined time period, for example, 1-year prevalence. The study had no definition of threats and violence, and the answers therefore depended on the doctors' subjective definition. However, this was likely to affect the results similarly both years.

\section{Comparison with other studies, possible explanations and implications}

The definition of categories of workplace violence varies between different studies, and direct comparison to other studies is therefore limited. However, our findings are comparable to studies which report work career prevalence of physical violence, giving proportions ranging from $11.3 \%$ to $32.0 \%,{ }^{810-12}$ whereas reported work career prevalence of threats of violence has been $46.0 \% .^{10}$

To our knowledge, only one other study has observed workplace violence in the healthcare sector over time. ${ }^{23}$ In accordance with our finding, this Italian study also reported stable prevalence of experienced physical aggression over the 5-year study period. Interestingly, the Italian study reported a significant reduction of lifetime experiences of threats. In our study, fewer doctors reported several experiences of threats of violence in 2014 compared with 1993. This might imply a trend towards lower prevalence of threats of violence. These findings oppose general beliefs about increasing violence, and the increase reported through public channels. ${ }^{457}$ Rather than reflecting real increase in workplace incidents, the increase in public reports could be a result of focus on workplace violence, less tolerance for incidents or an improved culture for reporting incidents. In dealing with the issue of workplace violence, there is a need to balance the description so as to prevent the construction of a new and unwarranted fear among healthcare workers. ${ }^{41}$ However, we need additional studies before we can conclude about the long-term changes in experienced violence. Long-term comparisons of 1-year prevalence 


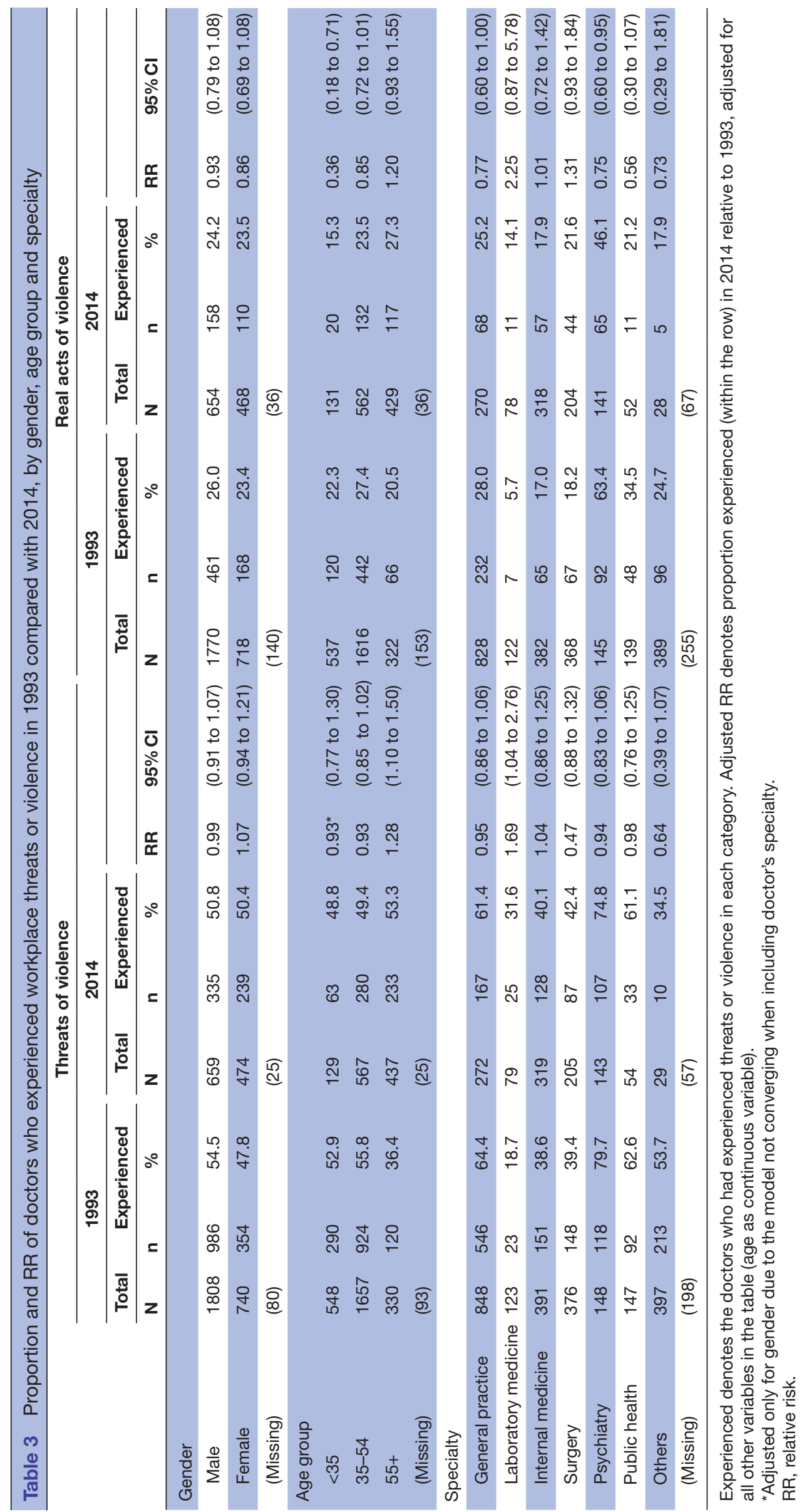


would increase the validity of the results. Further research should also explore the association between what people report when asked about experiences of workplace violence in general, and what they report when asked about exposure to specific acts of aggression. There is reason to believe that there is a discrepancy between what doctors actually experience and what they report as workplace violence. $^{742}$

In our study, there was a decrease from 1993 to 2014 in the proportion of doctors who reported being physically or psychologically unfit for last 12 months due to fear of violence, and this was unchanged when adjusted for gender, age and specialty. It could be that increased focus on and better management of workplace violence positively affect the personal outcome. Psychiatry has repeatedly been identified as the medical specialty most exposed to threats and violence. ${ }^{9} 232634$ Although our study confirms this observation, there was also a remarkable decrease in experienced acts of real violence from 1993 to 2014, without a similar change in experiences of threats. In Norwegian psychiatric settings, there has been a sustained focus on personnel security, which might have had a diminishing effect on real acts of violence, an effect which has not been observed in other countries. ${ }^{1}$ Other factors could also have contributed, such as changes in available medication, treatment methods or staffing or improved standards, for psychiatric care. The reported increase in experienced threats within laboratory medicine is difficult to explain and should be re-examined in studies of more suited designs.

\section{CONCLUSION}

Our study found no increase in workplace violence over time. Half of the doctors were exposed to threats of violence and one-fourth of the doctors had experienced real acts of violence at least once during their work career, which suggests that this aspect of the doctors' professional life should be commented on as part of their education. Furthermore, doctors' work settings need to have ways of reducing the impact and damage of workplace violence when it occurs. The substantial reduction of lifetime experiences of real acts of violence among psychiatrists suggests that programmes aimed at preventing violence work and that these should be applied in specialties with high occurrence of violence.

Acknowledgements We would like to express our gratitude to all the doctors who have participated in the surveys.

Contributors IHJ and TM conceived and designed the study. JR and OGA collected the data. IHJ and VB carried out the statistical analyses. IHJ drafted the manuscript and is the guarantor. All authors interpreted the data, critically revised the manuscript for important intellectual content and gave final approval of the version to be published.

Funding The study was funded by the Institute for Studies of the Medical Profession (LEFO), Oslo, Norway, and the National Centre for Emergency Primary Health Care, Uni Research, Bergen, Norway.

Competing interests None declared.
Ethics approval The study was approved by the Regional committee for medical and health research ethics (REF: IRB 0000 1870). All participating doctors gave informed consent. No copyright protected materials were used in the study.

Provenance and peer review Not commissioned; externally peer reviewed. Data sharing statement № additional data are available.

Open Access This is an Open Access article distributed in accordance with the Creative Commons Attribution Non Commercial (CC BY-NC 4.0) license, which permits others to distribute, remix, adapt, build upon this work non-commercially, and license their derivative works on different terms, provided the original work is properly cited and the use is non-commercial. See: http://creativecommons.org/ licenses/by-nc/4.0/

(c) Article author(s) (or their employer(s) unless otherwise stated in the text of the article) 2017. All rights reserved. No commercial use is permitted unless otherwise expressly granted.

\section{REFERENCES}

1. Cowman S, Björkdahl A, Clarke E, et al. A descriptive survey study of violence management and priorities among psychiatric staff in mental health services, across seventeen european countries. BMC Health Serv Res 2017;17:59.

2. Cooper C, Swanson N. Workplace violence in the health sector. state of the art. Geneva: Organización Internacional de Trabajo, Organización Mundial de la Salud, Consejo Internacional de Enfermeras Internacional de Servicios Públicos, 2002.

3. Wyatt R, Anderson-Drevs K, Van Male LM. Workplace Violence in Health Care: A critical issue with a promising solution. JAMA 2016;316:1037-8.

4. Andersen GR, Søvik SR. Dødsfall og personskader som følge av vold og trusler i norsk landbasert arbeidsliv - En oversikt basert på hendelser meldt til arbeidstilsynet. Trondheim: Direktoratet for Arbeidstilsynet, 2016. Contract No.: Nr. 1 2016. Norwegian.

5. Gomaa AE, Tapp LC, Luckhaupt SE, et al. Occupational traumatic injuries among workers in health care facilities - United States, 2012 2014. MMWR Morb Mortal Wkly Rep 2015;64:405-10.

6. Ambesh P. Violence against doctors in the Indian subcontinent: a rising bane. Indian Heart J 2016;68:749-50.

7. Dixon D. A five year analysis of physical assaults against NHS staff in England. SIRS/ RPA violence report 2010-2015. London: NHS Protect 2016.

8. Joa TS, Morken T. Violence towards personnel in out-of-hours primary care: a cross-sectional study. Scand J Prim Health Care 2012;30:55-60.

9. Wu S, Zhu W, Li H, et al. Workplace violence and influencing factors among medical professionals in China. Am J Ind Med 2012;55:1000-8.

10. Vorderwülbecke F, Feistle $\mathrm{M}$, Mehring $\mathrm{M}$, et al. Aggression and violence against primary care physicians - a nationwide questionnaire survey. Dtsch Arztebl Int 2015;112:159-65.

11. ALBashtawy M, Al-Azzam M, Rawashda A, et al. Workplace violence toward emergency department staff in Jordanian hospitals: a crosssectional study. J Nurs Res 2015;23:75-81.

12. Fisekovic MB, Trajkovic GZ, Bjegovic-Mikanovic VM, et al. Does workplace violence exist in primary health care? Evidence from Serbia. Eur J Public Health 2015;25:693-8.

13. Hobbs FD. Violence in general practice: a survey of general practitioners' views. BMJ 1991;302:329-32.

14. Carmi-lluz T, Peleg R, Freud T, et al. Verbal and physical violence towards hospital- and community-based physicians in the Negev: an observational study. BMC Health Serv Res 2005;5:54.

15. Kowalenko T, Walters BL, Khare RK, et al. Workplace violence: a survey of emergency physicians in the state of Michigan. Ann Emerg Med 2005;46:142-7.

16. Zafar W, Siddiqui E, Ejaz K, et al. Health care personnel and workplace violence in the emergency departments of a volatile metropolis: results from Karachi, Pakistan. J Emerg Med 2013;45:761-72.

17. Algwaiz WM, Alghanim SA. Violence exposure among health care professionals in Saudi public hospitals. A preliminary investigation. Saudi Med J 2012;33:76-82.

18. Hills DJ, Joyce CM, Humphreys JS. A national study of workplace aggression in Australian clinical medical practice. Med J Aust 2012;197:336-40.

19. Ferri $\mathrm{P}$, Silvestri M, Artoni $\mathrm{C}$, et al. Workplace violence in different settings and among various health professionals in an Italian 
general hospital: a cross-sectional study. Psychol Res Behav Manag 2016;9:263-75.

20. Hobbs FD. Fear of aggression at work among general practitioners who have suffered a previous episode of aggression. $\mathrm{Br} J$ Gen Pract 1994;44:390-4.

21. Coles J, Koritsas S, Boyle M, et al. GPs, violence and work performance - 'just part of the job?'. Aust Fam Physician 2007;36:189-91.

22. Kowalenko T, Gates D, Gillespie GL, et al. Prospective study of violence against ED workers. Am J Emerg Med 2013;31:197-205.

23. Magnavita N, Heponiemi T. Violence towards health care workers in a public health care facility in Italy: a repeated cross-sectional study. BMC Health Serv Res 2012;12:108.

24. Heponiemi T, Kouvonen A, Virtanen M, et al. The prospective effects of workplace violence on physicians' job satisfaction and turnover intentions: the buffering effect of job control. BMC Health Serv Res 2014;14:19.

25. Hills $\mathrm{D}$, Joyce $\mathrm{CM}$. Workplace aggression in clinical medical practice: associations with job satisfaction, life satisfaction and self-rated health. Med J Aust 2014;201:535-40.

26. Saeki K, Okamoto N, Tomioka K, et al. Work-related aggression and violence committed by patients and its psychological influence on doctors. J Occup Health 2011;53:356-64.

27. Gillespie GL, Bresler S, Gates DM, et al. Posttraumatic stress symptomatology among emergency department workers following workplace aggression. Workplace Health Saf 2013;61:247-54.

28. Wu S, Lin S, Li H, et al. A study on workplace violence and its effect on quality of life among medical professionals in China. Arch Environ Occup Health 2014:69:81-8.

29. Magin P, Bayley S, Sweatman J, et al. GP rural registrars' experiences of occupational violence: a qualitative study. Aust $J$ Rural Health 2010;18:249-50.

30. Magin PJ, Adams J, Ireland M, et al. After hours care--a qualitative study of GPs' perceptions of risk of violence and effect on service provision. Aust Fam Physician 2005;34:91-2.

31. Magin PJ, Adams J, Sibbritt DW, et al. Effects of occupational violence on Australian general practitioners' provision of home visits and after-hours care: a cross-sectional study. J Eval Clin Pract 2008;14:336-42.

32. Hobbs FD. General practitioners' changes to practice due to aggression at work. Fam Pract 1994;11:75-9.

33. Tolhurst $\mathrm{H}$, Talbot J, Baker L, et al. Rural general practitioner apprehension about work related violence in Australia. Aust J Rural Health 2003;11:237-41.

34. Arimatsu M, Wada K, Yoshikawa T, et al. An epidemiological study of work-related violence experienced by physicians who graduated from a medical school in Japan. J Occup Health 2008;50:E1.

35. Gale C, Arroll B, Coverdale J. Aggressive acts by patients against general practitioners in New Zealand: one-year prevalence. N Z Med J 2006;119:U2050.

36. Hills DJ, Joyce CM. Personal, professional, and work factors associated with Australian clinical medical practitioners' experiences of workplace aggression. Ann Occup Hyg 2013:57:898-912.

37. Aasland OG, Olff M, Falkum E, et al. Health complaints and job stress in Norwegian physicians: the use of an overlapping questionnaire design. Soc Sci Med 1997;45:1615-29.

38. LEFO - Legeforskningsinstituttet. The Doctor Panel . access date May 2017. http://legeforeningen.no/Legeforeningensforskningsinstitutt/ENGLISH/the-reference-panel-our-mostimportant-data-source/.

39. Rosta J, Aasland OG. Doctors' working hours and time spent on patient care in the period 1994 - 2014. Tidsskr Nor Laegeforen 2016;136:1355-9.

40. Rosta J, Aasland OG. Weekly working hours for Norwegian hospital doctors since 1994 with special attention to postgraduate training, work-home balance and the European working time directive: a panel study. BMJ Open 2014:4:e005704.

41. Mullen EA. Workplace Violence: cause for concern or the construction of a new category of fear? J Ind Relat 1997;39:21-32.

42. Morken T, Johansen IH, Alsaker K. Dealing with workplace violence in emergency primary health care: a focus group study. BMC Fam Pract 2015;16:51. 